\title{
Isoenzyme Profiles of Trypanosoma cruzi Stocks from Different Areas of Paraguay
}

\author{
Nidia Acosta, Margarita Samudio, Elsa López, Fernando Vargas*, \\ Nina Yaksic*, Simone Frédérique Brenière**, Antonieta Rojas de Arias/ ${ }^{+}$
}

Departamento de Medicina Tropical, Instituto de Investigaciones en Ciencias de la Salud (UNA), Casilla de Correo 2511, Asunción, Paraguay *Universidad Mayor de San Andrés, Instituto Boliviano de Biología de Altura, La Paz, Bolivia **UMR CNRS/ORSTOM N 9926, Mission ORSTOM Mexique, Los Morales, México DF

Twenty one Trypanosoma cruzi stocks from humans, domiciliary triatomines and one sylvatic animal of different areas of Paraguay were subjected to isoenzyme analysis. Thirteen enzyme systems (15 loci in total) were studied. MN cl2 (clonets 39) and SO34 cl4 (clonets 20) were used as references. Relationships between stocks were depicted by an UPGMA dendrogram constructed using the Jaccard's distances matrix. Among the Paraguayan stocks 14 zymodemes were identified (Parl to Par14), Par 5 being the most frequent. Polymorphism rate and clonal diversity were 0.73 and 0.93 , respectively. Average number of alleles per polymorphic locus was 2.5 (range 2-4). These measurements show a high diversity, which is confirmed by the dendrogram topology. All stocks belong to the same lineage, as MN cl2 reference strain (T. cruzi II). Moreover three distinct subgroups were identified and two of them correspond to Brazilian and Bolivian zymodemes, respectively. The third subgroup, the most common in Paraguay, is related to Tulahuen stock. The large geographical distribution of some zymodemes agrees with the hypothesis of clonality for $\mathrm{T}$. cruzi populations. However sample size was not adequate to detect genetic recombination in any single locality.

Key words: Trypanosoma cruzi - zymodemes - genetic polymorphism - clonality - Paraguay

Chagas disease is widely distributed in Latin America from the north of Mexico to the south of Argentina (Zeledón 1974). In Paraguay, like in many Latin American countries, the disease is an important public health problem, because there is a high number of Trypanosoma cruzi infected people and high triatomine infestation rates in dwellings (WHO 1986, Rojas de Arias 1996). Paraguay is located in the central part of South America and it is divided by the Paraguay River into two main regions: the Western or Chaco and the Eastern regions. Most of the population live in rural areas where living conditions make $T$. cruzi transmission easy. Triatoma infestans is the main vector and vector transmission is the most common way of acquiring the disease (Rojas de Arias 1996).

\footnotetext{
This study received financial support from the United Nations Development Program/World Bank/WHO Special Program for Research and Training in Tropical Disease (grant 940209).

${ }^{+}$Corresponding author Fax: +595-21-480-185. Email: sarias@conexion.com.py

Received 15 May 2000

Accepted 7 December 2000
}

The seroprevalence rates in endemic areas of Paraguay range from $14.3 \%$ in communities in the department of San Pedro (Canese 1973), 21.6\% in Paraguarí, 24.9\% in Cordillera (Rojas de Arias 1996) and $72.9 \%$ in an indigenous group of the Chaco region, the highest value recorded (Canese \& Brice 1977).

Limited studies have analyzed the $T$. cruzi stocks collected in different areas in Paraguay. Chapman et al. (1984) related T. cruzi stocks isolated in the Presidente Hayes department of the Paraguayan Chaco to the Bolivian zymodeme 2. Yamasaki et al. (1990) described similar schizodeme profiles of three isolates from acute Chagas patients from distant geographical areas and related to a Brazilian strain. Mimori et al. (1992) found four distinct schizodeme groups among eleven stocks and matched two of them with the Brazilian zymodeme 2. In a previous study, Acosta et al. (1995) carried out metacyclogenesis, experimental infection in mice, lectin agglutination, parasitemic curves and morphometry with $T$. cruzi stocks from acute cases in humans, and found a great variability, especially in the biological behavior. Analysis of the geographical distribution of $T$. cruzi is often difficult because of lack of standardization of techniques, studies with reduced loci, absence of phylogenetic studies and lack of the 
same reference strains (Barnabé \& Brenière 1999). The present study analyzes the isoenzyme profiles of $21 \mathrm{~T}$. cruzi stocks mainly from the domestic cycle of different localities in Paraguay. Identical loci and similar electrophoretic conditions were used as previously to analyze large samples of $T$. cruzi from diverse origins. This allows easier identification of the taxonomic position of the Paraguayan stocks.

\section{MATERIALS AND METHODS}

Parasite stocks - Twenty one stocks from different regions of Paraguay were studied (Fig. 1). Twelve stocks belonged to human cases, eight stocks to domestic $T$. infestans and one stock to a domesticated yellow armadillo. The origin of each stock is shown in Table I. SO34 cl4 (clonets 20) and MN cl2 (clonets 39), previously typed (Brenière et al. 1998), were used as reference strains. These clones are genetically well separated and they belong to $T$. cruzi I and T. cruzi II groups, respectively (Anon 1999). They correspond to major clones frequently isolated in South America and they are the main clones found in the domestic Bolivian cycle (Tibayrenc \& Brenière 1988, Brenière et al. 1998)

Isolation and maintenance of the stocks - The stocks were obtained by hemoculture, xenoculture and mice inoculation, maintained and amplified at $28^{\circ} \mathrm{C}$ in LIT medium (liver infusion tryptose) (Camargo 1964) with $50 \mu \mathrm{g} / \mathrm{l}$ of hemin, supplemented with $20 \%$ fetal bovine serum, 100 UI of penicillin and $100 \mu \mathrm{g}$ of streptomycin per $\mathrm{ml}$ of medium.

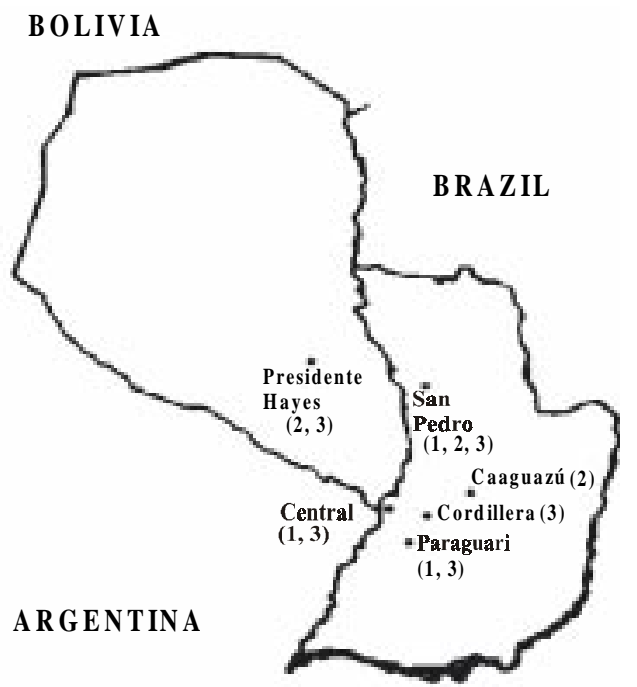

Fig. 1: geographical location of the different Paraguayan stocks. 1, 2 and 3 correspond to the subgroups of zymodemes found.
Isoenzyme analysis - Parasite pellet was harvested in the growth peak day and washed twice with PBS at $3,000 \mathrm{rpm}, 4^{\circ} \mathrm{C}$ for $10 \mathrm{~min}$. The pellet was kept at $-80^{\circ} \mathrm{C}$ until used. At the time of electrophoresis it was diluted in an equal volume of protein stabilizer solution containing $2 \mathrm{mM} \varepsilon$ amino caproic acid, EDTA and dithiothreitol.

Electrophoresis was carried out in cellulose acetate plates (Helena, Beaumont, TX) as previously described (Tibayrenc \& Le Ray 1984). Thirteen enzymatic systems were studied: glucose phosphate dehydrogenase (G6PD, EC.1.1.1.49), glucose phosphate isomerase (GPI, EC.5.3.1.9), glutamate dehydrogenase NAD (GDH1, EC.1.4.1.2., glutamate dehydrogenase NADP+ (GDH 2, EC.1.4.1.4), isocitrate dehydrogenase (IDH, EC.1.1.1.42), malate dehydrogenase (MDH, EC.1.1.1.37), malic enzyme (ME, EC.1.1.1.40.), peptidase (PEP 1, EC.3.4.11.11), peptidase (PEP 1+2, EC.3.4.11.13), phosphoglucomutase (PGM, EC.2.7.5.1), 6-phosphogluconate dehydrogenase, (6PGD, EC.1.1.1.44), diaphorase (DIA, EC.1.6.---), aspartate aminotransferase (GOT, EC.2.6.1.1).

The genotypes were assigned according to the profiles in the cellulose acetate plates with the already mentioned criteria of genotype numbers (Tibayrenc \& Ayala 1988): band 1 corresponded to the smallest distance from the anode.

The observed heterozygosity was estimated by the following formula: $\mathrm{Ho}=\mathrm{ho} /(\mathrm{N} \mathrm{x} \mathrm{r})$, where ho $=$ total number of heterozygous observed, $\mathrm{N}=$ number of stocks and $\mathrm{r}=$ number of loci studied. The expected heterozygosity was estimated by the following relation: $\mathrm{H}=\sum_{1}^{\mathrm{r}} \mathrm{h} / \mathrm{r}$, where $\mathrm{h}=\sum_{1}^{1} 1-\mathrm{qi}^{2}$, and $r=$ number of loci and qi $=$ frequency of the allele "i" in locus " $r$ ".

The polymorphism rate was determined by the relation: no. of polymorphic loci/no. of studied loci. The clonal diversity was measured by Whittam's (Whittam 1989) index which is equal to: $\mathrm{d}=\mathrm{n}\left(1-\Sigma \mathrm{Xi}^{2}\right) /(\mathrm{n}-1)$, where $\mathrm{Xi}=$ frequency of each zymodeme and $n=$ no. of stocks. This index measures the probability of obtaining stocks from different zymodemes when performing sampling the study population. The average of alleles per locus was calculated by the relation: $\Sigma \mathrm{a}_{\mathrm{r}} / \mathrm{r}$, where $\mathrm{a}_{\mathrm{r}}=$ no. of alleles per locus and, $\mathrm{r}=$ no. of studied loci.

In order to estimate the genetic divergence between zymodemes, Jaccard's phenetic distance was (Jaccard 1908): $\mathrm{d}=1-(\mathrm{C} / 2 \mathrm{~N}-\mathrm{C})$, where $\mathrm{C}=$ no. of common bands between two zymodemes and $\mathrm{N}=$ no. of total bands of both zymodemes. The UPGMA (unweighted pair-group method with arithmetic averages) (Sneath \& Sokal 1973) was used to cluster the zymodemes according to 
Jaccard's distances matrix. The dendrogram was built using Mac Dendro (Thioulouse 1989).

\section{RESULTS}

Genotype variability - Among the 13 enzyme systems tested, two (ME and DIA) made it possible to infer the activity of two different loci, consequently, the analysis of 15 putative loci in total was performed. Tables I and II show the multilocus genotypes of the 23 studied stocks deduced from the isoenzyme profiles obtained; stocks that showed identical isoenzymatic patterns for all the enzyme systems belong to the same zymodeme. Fifteen distinct zymodemes were identified including the two reference stocks $\mathrm{MN} \mathrm{cl} 2$ and SO34 cl4 which belong to Par1 and Par15, respectively.

Among the Paraguayan stocks, four loci were monomorphic (Mdh, Pep 2, Got, Dia 1) and the polymorphism rate was 0.73 . Regarding the 11 variable loci, the average number of alleles per locus was 2.5 (range 2-4). Several patterns observed for Gpi, Idh, Pgm and 6pgd loci were characteristic of heterozygotes, and the observed heterozygosity was 0.17 . The average value of expected heterozygosity was 0.34 ; a deficiency of heterozygotes was hence apparent. The number of stocks belonging to a single zymodeme range from
1 to 6 for Par 5 and the probability of sampling two different zymodemes in the population measured by the Whittam's index was 0.93 .

Phenetic relationships - The dendrogram (Fig. 2) based on the Jaccard's distance matrix showed two upper branches which included a reference stock each. They correspond to the two principal groups of $T$. cruzi previously described (Tibayrenc 1995, Brenière et al. 1998). All the Paraguayan stocks belong to the T. cruzi II as MN cl2 reference stock. Moreover, T. cruzi II, presented three separated branches (subgroups 1 to 3 ) with distances ranging from 0.35 to 0.65 between them (Fig. 2). Four stocks were closely related to $\mathrm{Mn}$ cl2 reference stocks (subgroup 1) which belong to the most common zymodeme (clonets 39) found in the domestic Bolivian cycle. Except the Arma 134 (the only stock isolated from a sylvatic mammal) all the stocks of subgroups 1 and 2 presented variable heterozygote patterns for the Gpi locus and those of subgroups 3 had the same homozygous profile (genotype 2/2, Gpi locus). The distribution of zymodemes according to their hosts and geographical origin is shown in Figs 1 and 2. An absence of specific geographical distribution of the zymodeme groups was observed, since for example zymodemes belonging to subgroup 2 were found

TABLE I

Origin of the Trypanosoma cruzi stocks examined

\begin{tabular}{|c|c|c|c|c|}
\hline Stocks & Department & Host & Zym & Sub-group \\
\hline $\mathrm{HV}$ & Caaguazú & Human (acute) & Par 9 & 2 \\
\hline ROFI & Central & Human (acute transfusional) & Par 13 & 3 \\
\hline $\mathrm{JM}$ & Central & Human (acute transfusional) & Par 14 & 3 \\
\hline RN Lezcano & Central (mother from San Pedro) & Human (congenital) & Par 1 & 1 \\
\hline JAG & Cordillera & Human (acute) & Par 13 & 3 \\
\hline DG & Paraguarí & Human (indeterminate) & Par 10 & 3 \\
\hline Xc 116 & Paraguarí & Triatoma infestans & Par 2 & 1 \\
\hline FALE & Paraguarí & Human (indeterminate) & Par 3 & 1 \\
\hline GS & Presidente Hayes & Human (acute) & Par 11 & 3 \\
\hline Xc ILSE & Presidente Hayes & Human (acute) & Par 5 & 2 \\
\hline LAURA & Presidente Hayes & Human (acute) & Par 5 & 2 \\
\hline Coraí 6 & Presidente Hayes & Triatoma infestans & Par 5 & 2 \\
\hline Coraí 14 & Presidente Hayes & Triatoma infestans & Par 5 & 2 \\
\hline Lengua 15 & Presidente Hayes & Triatoma infestans & Par 5 & 2 \\
\hline Coraí 7 & Presidente Hayes & Triatoma infestans & Par 6 & 2 \\
\hline Coraí s/n & Presidente Hayes & Triatoma infestans & Par 7 & 2 \\
\hline Lengua 16 & Presidente Hayes & Triatoma infestans & Par 7 & 2 \\
\hline Coraí 18 & Presidente Hayes & Triatoma infestans & Par 8 & 2 \\
\hline $\mathrm{EV}$ & San Pedro & Human (chronic) & Par12 & 3 \\
\hline ARMA 134 & San Pedro & $\begin{array}{l}\text { Euphractus sexcintus } \\
\text { (yellow armadillo) }\end{array}$ & Par 4 & 1 \\
\hline EMI & San Pedro & Human (acute) & Par 5 & 2 \\
\hline $\mathrm{SO} 34 \mathrm{cl}^{a}$ & Potosi (Bolivia) & Triatoma infestans & Par 15 & \\
\hline $\mathrm{MN} \operatorname{cl} 2^{a}$ & IV Region (Chile) & Human (chronic) & Par 1 & 1 \\
\hline
\end{tabular}

a: laboratory clones 20 (SO34 cl4) and 39 (MN cl2) used as references (Tibayrenc \& Ayala 1988). 


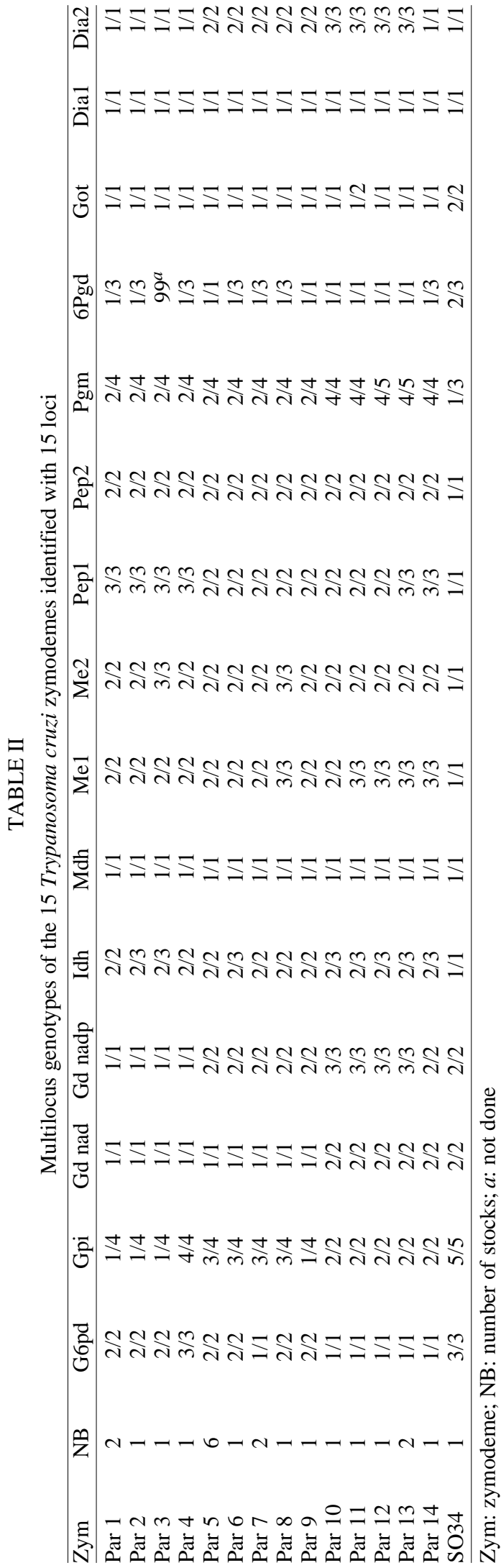

in Presidente Hayes, San Pedro and Caaguazú departments, and zymodemes of the three subgroups were observed in the San Pedro department. Regarding the host, all the studied stocks (except one) were from human cases and $T$. infestans which is the principal vector in Paraguay. Therefore all these stocks can be considered as part of the domestic cycle. As expected similar zymodemes and closely related zymodemes could be found in $T$. infestans and human (eg. Par 5) but zymodemes of subgroups 3 were only isolated from humans. Nevertheless, such a host specificity must be verified with larger samples of stocks.

\section{DISCUSSION}

The isoenzyme technique has been widely used to characterize $T$. cruzi populations of different countries belonging to domestic and sylvatic cycles (Miles et al. 1980, Tibayrenc \& Miles 1983, Carneiro et al. 1991, De Luca D'oro et al. 1993, Lewicka et al. 1995, Brenière et al. 1997) but limited data are available from Paraguayan stocks. The comparison of isoenzyme data with other genetic markers gave congruent results and showed the division of $T$. cruzi taxon into two principal groups (Tibayrenc 1995, Souto et al. 1996, Brisse et al. 1998, Breniére et al. 1998). According to the analysis of MLEE data (22 loci) and RAPD (10-mer primers) together $T$. cruzi I and T. cruzi II present high bootstrap values (97\% and 93\% respectively), a strong support of the T. cruzi division in two lineages; the $\mathrm{SO} 34$ cl 4 stock belongs to T. cruzi I and $\mathrm{MN} \mathrm{cl} 2$ to $T$. cruzi II. In the present study, the isoenzyme analysis of 15 loci allowed the classification of the 21 Paraguayan stocks into 14 zymodemes and the estimation of the degree of genetic differentiation among them. All the stocks were clustered in an upper branch with the MN cl 2 stock used as control and none of them were genetically related to the SO34 cl4 stock. Moreover, the comparison of the distances with previous data show that the Paraguayan stocks can be considered as belonging to T. cruzi II. Nevertheless, among the stocks, genetic diversity is still important, and three subgroups were observed. Previous analysis also showed that group T. cruzi II presents a high genetic diversity and Tibayrenc (1998) proposed five subgroups. The relationship between these subgroups and the three Paraguayan subgroups is more difficult to interprete. Nevertheless, it is worth noting that the stocks belonging to subgroups 1 and 2 have heterozygous profiles for Gpi, Pgm and $6 P g d$ loci, hence they should correspond to two different zymodemes named Z39 and Z43 by Tibayrenc (1998): Z39 include MN cl2 stock and Z43 include the laboratory reference strain Tulahuen. The remaining Paraguayan stocks are clustered apart and 

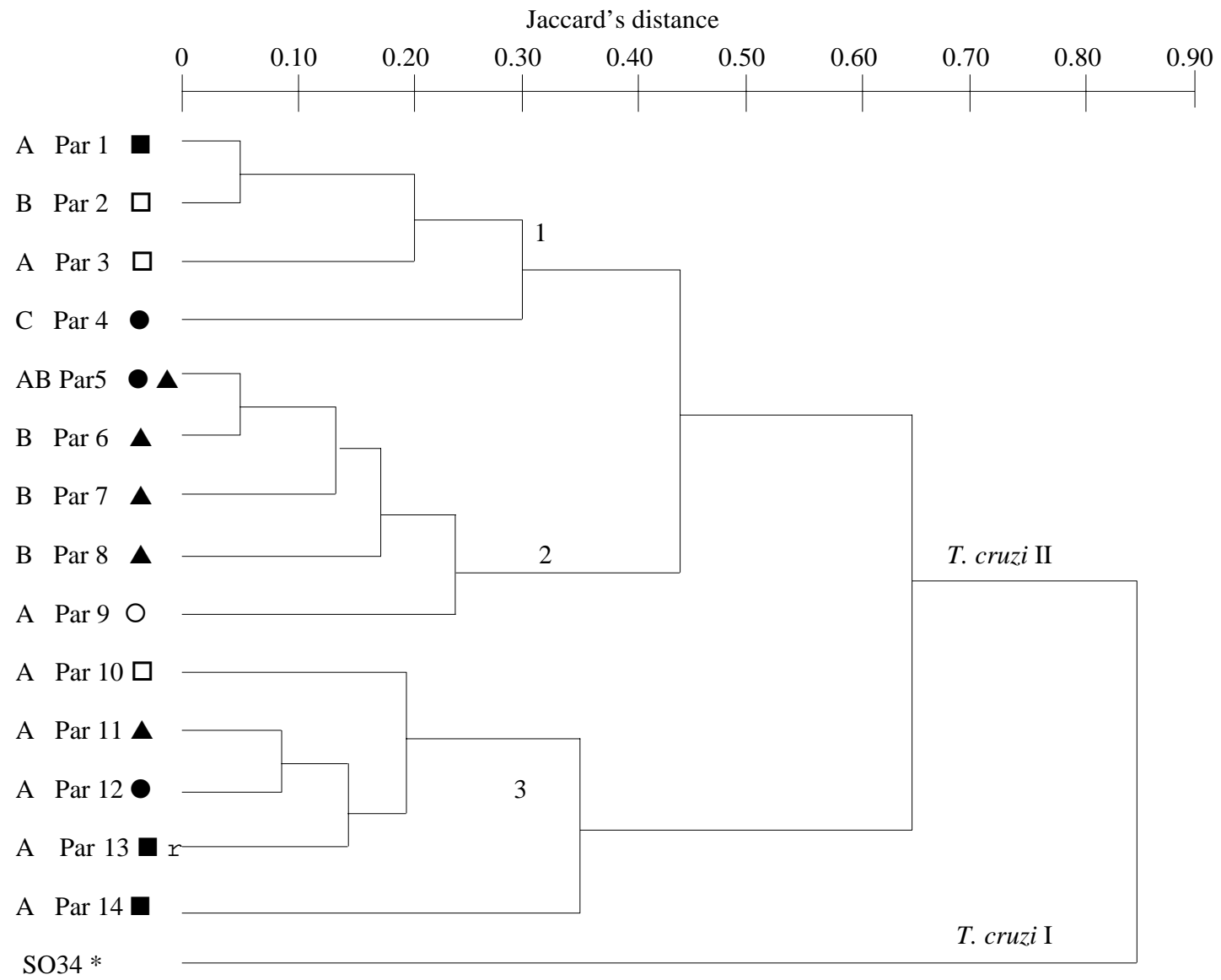

Fig. 2: dendrogram constructed by the hierarchical ascending method UPGMA from Jaccard's distance matrix (15 loci), for 21 Trypanosoma cruzi zymodemes. Host and geographical origins are indicated for each zymodeme. A: human, B: Triatoma infestans; C: Euphractus sexcintus (armadillo); $\boldsymbol{\Delta}$ : Presidente Hayes; O: San Pedro; r: Cordillera; $\mathbf{\square}$ : Central; O: Caaguazu; $\square$ : Paraguari. 1, 2 and 3 correspond to the subgroups ;*: reference stock (SO34)

did not present heterozygous patterns (subgroup 3) but gave the same profile as Esmeraldo cl3 stock (Brazilian Z2 reference) at Gpi and $6 P g d$ loci which was previously characterized by Brenière et al. (1998). Previous analysis of Paraguayan T. cruzi stocks by isoenzyme (Chapman et al. 1984) and restriction enzyme analysis of kinetoplast DNA (Yamashi et al. 1991, Mimori et al. 1992) showed that the stocks shared most features of the Bolivian Z2 and Brazilian Z2 T. cruzi stocks. More recent works showed that these zymodemes belong to T. cruzi II (Brenière et al. 1998), but are clustered apart in distinct subgroups (Tibayrenc \& Miles 1983, Barnabé \& Brenière 1999): Bolivian $\mathrm{Z} 2$ and Brazilian Z2 belong to Z39 and Z32, respectively, according to Tibayrenc (1998). The present and previous results agree with the presence in Paraguay of stocks genetically related to: (i) the Brazilian Z2 (subgroup 3) (ii) Bolivian stocks pertaining to one of the most frequent clone circulating in the Bolivian domestic cycle (clonets 39) (Brenière et al. 1995, 1998) (subgroup 1); and (iii) Tulahuen reference stock (subgroup 2). The stocks belonging to the latter were the most abundant in Paraguay (50\% of the studied sample).

High genetic variability in the studied population was confirmed by the index of polymorphism and Whittam's which are similar to others found in other countries (Tibayrenc \&Ayala 1988, De Luca D'Oro et al. 1993, Brenière et al.1997).

The criteria of clonality for $T$. cruzi populations has been widely described in several studies (Tibayrenc \& Desjeux 1983, Tibayrenc et al. 1984, Tibayrenc \& Ayala 1988). The results obtained in this study agree with this hypothesis. A stock isolated from a human case of San Pedro department presented the same genotype as stocks from human and triatomines of Presidente Hayes depart- 
ment. These two regions are geographically separated by the Paraguay River (see Fig. 1). In the same way, the stock RN Lezcano showed the same profiles as $\mathrm{MN}$ cl 2 reference strain isolated in other countries and at different times. Also, the possibility of contamination was minimal because the parasites were processed separately by different laboratories. The fact of finding stocks with the same profile in geographically distant areas and isolated in different moments confirms the ubiquitous feature of these zymodemes which is one of the clonality criteria (Tibayrenc \& Ayala 1988). The difference between expected and observed heterozygosity values also supports the clonality. Some studies suggest genetic exchanges in this organism (Bogliolo et al. 1996, Carrasco et al. 1996). The clonal model does not exclude the possibility of the occurrence of genetic exchange. It is only that the exchange is not frequent enough for the current genotypes or zymodemes to be considered unstable or transient entities.

The identification of the clonal types of circulating $T$. cruzi and their geographical distribution are important for the study of Chagas disease. Based on clonal types main and secondary species of vector can be identified, the relationship between wild and domestic cycles can be evaluated, reservoirs can be identified and the observed pathologies can be compared (Barnabé \& Brenière 1999).

\section{ACKNOWLEDGMENTS}

To Luis Sanabria, Alba Inchaustti, Ma. Elena Ferreira for their cooperation in the isolation of the stocks used in this work; to Dr Marisel Maldonado for revising the English of the manuscript. To the technical staff of the Department of Tropical Medicine: Pedro Recalde, Elvio Benítez, Victoria Bogado and Jazmina Rivarola for their valuable cooperation.

\section{REFERENCES}

Acosta N, Maldonado M, Sanabria L, Yaluff G, Fuentes S, Torres S, Ferreira ME, Rojas de Arias A, Shozawa T 1995. Characterization of Paraguayan Trypanosoma cruzi strains isolated from acute patients of Chagas disease. Trop Med Parasitol 46: 195-200.

Anon 1999. Recommendations from a Satellite Meeting. Mem Inst Oswaldo Cruz 94: 429-432.

Barnabé C, Brenière SF 1999. Ecodistribución de los clones de Trypanosoma cruzi. In JR Alfred Cassab, F Noireau, G Guillén (eds), Chagas. La Enfermedad en Bolivia,Conocimientos Científicos al Inicio del Programa de Control (1998-2002), Ediciones Gráficas "E.G.”, La Paz, p. 209-215.

Bogliolo AR, Lauria-Pires L, Gibson W 1996. Polymorphisms in Trypanosoma cruzi: evidence of genetic recombination. Acta Trop 61: 31-40.

Brenière SF, Bosseno MF, Telleria J, Carrasco R, Vargas F, Yaksic N, Noireau F 1995. Field application of PCR diagnosis and strain typing of Trypanosoma cruzi in Bolivian triatomines. Am J Trop Med Hyg 53: $179-184$.

Brenière SF, Bosseno MF, Telleria J, Bastrenta B, Yaksic $\mathrm{N}$, Noireau F, Alcazar JL, Barnabé C, Wincker P, Tibayrenc M 1998. Different behavior of two Trypanosoma cruzi major clones: transmission and circulation in Bolivian young patients. Exp Parasitol 89: 285-295.

Brenière S, López J, Vargas F, Barnabe C 1997. Genetic variability and microdistribution of Triatoma infestans genotypes and Trypanosoma cruzi clones in Arequipa Region (Perú). Mem Inst Oswaldo Cruz 92: 401-408.

Brisse S, Barnabé C, Tibayrenc M 1998. Trypanosoma cruzi: how many relevant phylogenetic subdivisions are there? Parasitol Today 14: 178-179.

Camargo E 1964. Growth and differentiation in Trypanosoma cruzi I. Origen of metacyclic trypanosomes in liquid media. Rev Inst Med Trop São Paulo 6: 93-100.

Canese A 1973. Epidemiología de la enfermedad de Chagas en el Paraguay. Rev Parag de Microbiol 8: 13-18.

Canese J, Brice E 1977. Diagnóstico de la enfermedad de Chagas en aborígenes del Chaco paraguayo. Rev Parag de Microbiol 11: 9-10.

Carneiro M, Romanha AJ, Chiari E 1991. Biological characterization of Trypanosoma cruzi strains from different zymodemes and schizodemes. Mem Inst Oswaldo Cruz 86: 387-393.

Carrasco HK, Frame IA, Valente SA, Miles MA 1996. Genetic exchange as a possible source of genomic diversity in sylvatic populations of Trypanosoma cruzi. Am J Trop Med Hyg 54: 418-424.

Chapman M, Baggaley R, Godfrey-Fausset P, Malpas T, White G, Canese J, Miles M 1984. Trypanosoma cruzi from the Paraguayan Chaco: isoenzyme profiles of strains isolated at Makthlawaiya. J Protozool 3: $482-486$.

De Luca D' Oro GM, Gardenal CN, Perret B, Crisci JV, Montamat E 1993. Genetic structure of Trypanosoma cruzi populations from Argentina estimated from enzyme polymorphism. Parasitology 107: 405410.

Jaccard P 1908. Nouvelles recherches sur la distribution florale. Bull Soc Vaudoise Sc Nat 44: 223-270.

Lewicka K, Brenière S, Barnabe C, Dedet JP, Tibayrenc M 1995. An isoenzyme survey of Trypanosoma cruzi genetic variability in sylvatic cycles from French Guiana. Exp Parasitol 8: 20-28.

Miles MA, Lanham SM, Souza AA de, Povoa M 1980. Further enzymic characters of Trypanosoma cruzi and their evaluation for strain identification. Trans $R$ Soc Trop Med Hyg 74: 221-236.

Mimori T, Maldonado M, Samudio M, Rojas de Arias A, Moreno R, Sakamoto M 1992. Characterization of Trypanosoma cruzi isolates from Paraguay, using restriction enzyme analysis of kinetoplast DNA. Ann Trop Med Parasitol 86: 231- 327.

Rojas De Arias A 1996. Chagas disease in Paraguay. $\mathrm{PAHO} / \mathrm{HCP} / \mathrm{HCT} / 72 / 96$.

Sneath PHA, Sokal RR 1973. Numerical taxonomy. In 
D Kennnedy, RB Park (eds), The Principles and Practice of Numerical Classification, Freeman and Company, San Francisco, 359 pp.

Souto RP, Fernandes O, Macedo AM, Campbell DA, Zingales B 1996. DNA markers define two major phylogenetic lineages of Trypanosoma cruzi. Mol Biochem Parasitol 83: 141-152.

Thioulouse J 1989. Statistical analysis and geographical display of multivariate data on Macintoch. Computer Apply Biosciences 5: 287-292.

Tibayrenc M 1995. Population genetics of parasitic protozoa and other microorganisms. Adv Parasitol 36: 47-115.

Tibayrenc M 1998. Genetic epidemiology of parasitic protozoa and other infectious agents: the need for integrated approach. Intern J Parasitol 28: 85-104.

Tibayrenc M, Ayala FJ 1988. Isozyme variability in $T$. cruzi, the agent of Chagas disease: genetical, taxonomical and epidemiological significance. Evolution 42: 277-292.

Tibayrenc M, Brenière S 1988. Trypanosoma cruzi: major clones rather than principal zymodemes. Mem Inst Oswaldo Cruz 83 (Suppl. I): 249-255.

Tibayrenc M, Desjeux P 1983. The presence in Bolivia of two distinct zymodemes of Trypanosoma cruzi, circulating sympatrically in a domestic transmission cycle. Trans $R$ Soc Trop Med Hyg 77: 73-75.

Tibayrenc M, Miles M 1983. A genetic comparison between Brazilian and Bolivian zymodemes of Trypanosoma cruzi. Trans $R$ Soc Trop Med Hyg 77: 76-83.
Tibayrenc M, Le Ray D 1984. General classification of the isoenzymic strains of Trypanosoma (Schizotrypanum) cruzi and comparision with T.(S.) $c$. marinkellei and T.(Herpetosoma) rangeli. Ann Soc Belge Méd Trop 64: 239-248.

Tibayrenc M, Echalar L, Dujardin JP, Poch O, Desjeux $\mathrm{P}$ 1984. The microdistribution of isoenzymic strains of Trypanosoma cruzi in southern Bolivia; new isoenzyme profiles and further arguments againts Mendelian sexuality. Trans $R$ Soc Trop Med Hyg 78: 519-525.

Whittam TS 1989. Clonal dymamics of Escherichia coli in its natural habitat. Antonie van Leeuwenhock 55: 23-32.

WHO-World Health Organization 1986. Research activities of the scientific working group (SWG) on Chagas disease 1982-1985. Report of the streering committes (SC) to the scientific and technical rewiew (STRC). Mem Inst Oswaldo Cruz 81(Suppl. I): 211212.

Yamasaki H, Kita K, Aoki T, Oya H, Pavón B, Arias O, Morán M, Vera M 1990. Schizodeme characterization of kinetoplast DNA minicircles of Trypanosoma cruzi and Leishmania isolates from Paraguayan Chagas' disease and leishmaniasis patients. Japan J Trop Med Hyg 18: 62-63.

Zeledón R 1974. Trypanosomiasis and leishmaniasis with special reference to Chagas' disease. Ciba Foundation Symposium 20 (new series) Elsevier, Experta Medica, North-Holland, Amsterdam. 
534 Isoenzymes of T. cruzi from Paraguay - Nidia Acosta et al. 